\title{
Atypical carcinoid tumours of the lung: prognostic factors and patterns of recurrence
}

\author{
M A Cañizares, ${ }^{1}$ J M Matilla, ${ }^{2}$ A Cueto, ${ }^{3}$ J Algar, ${ }^{4}$ I Muguruza, ${ }^{5}$ N Moreno-Mata, ${ }^{6}$ \\ R Moreno-Balsalobre, ${ }^{7}$ R Guijarro, ${ }^{8}$ R Arrabal, ${ }^{9}$ E Garcia-Fontan, ${ }^{1}$ \\ A Gonzalez-Piñeiro, ${ }^{1}$ M Garcia-Yuste, ${ }^{2}$ EMETNE-SEPAR Members ${ }^{10}$
}

For numbered affiliations see end of article.

\section{Correspondence to} Dr Miguel A Cañizares, Thoracic-Surgery Department, University Hospital, Pizarro 22, Vigo 36204, Spain; miguel.a.canizares@gmail.com

Received 19 July 2013 Revised 30 January 2014 Accepted 6 February 2014 Published Online First 6 March 2014
CrossMark

To cite: Cañizares MA, Matilla JM, Cueto A, et al. Thorax 2014;69:648-653.

\section{ABSTRACT}

Background Atypical carcinoids (AC) of the lung are rare intermediate-grade neuroendocrine neoplasms. Prognostic factors for these tumours are undefined. Methods Our cooperative group retrieved data on 127 patients operated between 1980 and 2009 because of an AC. Several clinical and pathological features were studied.

Results In a univariable analysis, T-status ( $p=0.005)$, $\mathrm{N}$-status ( $p=0.021$ ), preoperative M-status (previously treated) ( $p=0.04)$, and distant recurrence developed during the outcome $(p<0.001)$ presented statistically significant differences related to survival of these patients. In a multivariable analysis, only distant recurrence was demonstrated to be an independent risk factor for survival $(p<0.001 ;$ HR: 13.1). During the monitoring, $25.2 \%$ of the patients presented some kind of recurrence. When we studied recurrence factors in a univariable manner, sublobar resections presented significant relationship with locoregional recurrence $(p<0.001)$. In the case of distant recurrence, T and N status presented significant differences. Patients with preoperative M1 status presented higher frequencies of locoregional and distant recurrence $(p=0.004$ and $p<0.001$, respectively). In a multivariable analysis, sublobar resection was an independent prognostic factor to predict locoregional recurrence ( $p=0.002 ;$ HR: 18.1$)$.

Conclusions Complete standard surgical resection with radical lymphadenectomy is essential for AC. Sublobar resections are related to locoregional recurrence, so they should be avoided except for carefully selected patients. Nodal status is an important prognostic factor to predict survival and recurrence. Distant recurrence is related to poor outcome.

\section{INTRODUCTION}

Atypical carcinoids (ACs) of the lung are rare intermediate-grade neoplasms which are part of a wide spectrum of neuroendocrine tumours ranging from the typical carcinoid to small cell lung carcinoma. Although this type of neoplasm can be found throughout the body, the bronchial tree is the most frequent location for approximately $25 \%$ of carcinoid tumours. ${ }^{1}$

In 1998, Arrigoni's ${ }^{2}$ long-standing histological criteria for the diagnosis of AC (presence of five or more mitoses in $2 \mathrm{~mm}^{2}$ or focal necrosis) $)^{2}$ were modified by Travis and colleagues and then accepted by WHO and the International Association for the Study of Lung Cancer (IASLC)
Key messages

What is the key question?

- What clinical factors are affecting prognosis in atypical carcinoids of the lung, related to survival and recurrence?

What is the bottom line?

- Complete lobar surgical resection, $\mathrm{N}$ and $\mathrm{M}$ status remain as main behaviour markers.

\section{Why read on?}

- Although there is no consensus about what prognostic marker should be observed, our series is probably one of the largest series published to date about this infrequent tumour.

in 1999. Atypical carcinoid was thence defined as a tumour with neuroendocrine morphology and mitotic counts of two or more and less than 10 per $2 \mathrm{~mm}^{2}$ of viable tumour (10 high-power fields), or the presence of punctate foci of coagulative necrosis. ${ }^{3}$ Large areas of geographic necrosis typical of high-grade neuroendocrine carcinomas are not seen. ${ }^{4}$

Although the aggressive behaviour of AC is well known, factors predisposing to poor prognosis are uncertain. Regional disease with spread to local lymph nodes occurs frequently in AC tumours. Published studies related a variable rate of lymph node disease of anywhere from $20 \%$ to $60 \%$ of cases. $^{5-7}$ Nevertheless, the main prognostic factors in these neoplasms are undefined in the literature. We present our experience in this kind of neuroendocrine tumours.

\section{MATERIAL AND METHODS}

The Spanish Multicenter Study of Neuroendocrine Tumours of the Lung (EMETNE is the Spanish acronym) is a cooperative multicenter group composed of 26 hospitals throughout Spain. All resected neuroendocrine lung tumours at any of the participating institutions from 1980 were registered and classified into one of the following categories: typical carcinoid, AC, large cell neuroendocrine carcinoma (LCNEC), and small cell lung carcinoma. We collected 127 AC tumours that were operated between 1980 and 2009. Before 
1998, cases were retrieved retrospectively. From 1998, new cases were collected in a prospective manner. Local lung pathologists reviewed all samples to classify them following the 1999 WHO classification, including Travis's new criteria for AC. Patients underwent complete surgical resection of the tumour in all cases. From 1980 to 1997, a mediastinal lymph node sampling was associated. In the prospective group, systematic nodal dissection was carried out.

We studied clinical behaviour in these tumours, analysing prognostic significance and patterns of nodal affection and recurrence. Clinical variables considered were: age, gender, location of the tumour, size, surgical procedure and nodal status using the tumour-node-metastasis (TNM) classification. ${ }^{8}$ Histological feature variables were: tumour differentiation, tumour pattern, angio-lymphatic invasion and immunohistochemical markers (chromogranin, synaptophysin and neuronspecific enolase in all cases). The resection extent was also studied, dividing the series into lobar resections (LR) (lobectomy, bi-lobectomy and pneumonectomy) and sublobar resections (SR) (segmentectomy and isolated bronchial resection), as well as adjuvant treatment (chemotherapy (ChT), and radiotherapy (RT)). Survival analysis data were collected from a systematic follow-up database. Local recurrence and distant metastasis were also assessed.

Statistical analysis was carried out using a SPSS V.19.0 statistical package programme. Categorical variables were compared using $\chi^{2}$ test. Mean differences were assessed using $t$ test or analysis of variance. Cumulative survival probabilities were estimated by the Kaplan-Meier test. A multivariable analysis was performed in order to determine prognostic factors using linear regression or Cox's regression. A $\mathrm{p}$ value of $<0.05$ was considered significant.

\section{RESULTS}

From the 1082 patients affected by a neuroendocrine lung tumour registered in our database in December 2009, 127 corresponded to an AC. These represent $11.7 \%$ of total cases. Demographics and clinical features are given in table 1. Bronchoscopy was the main diagnostic procedure. In 72 cases $(56.7 \%)$, the tumour was visualised endoscopically. Bronchial

Table 1 Demographics and clinical characteristics

\begin{tabular}{|c|c|}
\hline Age & Mean: 53.07 years; SD: $16.457(\%)$ \\
\hline Gender & $\begin{array}{l}\text { Male: } 69(54.3) \\
\text { Female: } 58(45.7)\end{array}$ \\
\hline Location & $\begin{array}{l}\text { Central: } 72(56.7) \\
\text { Peripheral: } 55 \text { (43.3) }\end{array}$ \\
\hline Symptoms & $\begin{array}{l}\text { Symptomatic: } 87 \text { (68.5) } \\
\text { Asymptomatic: } 40 \text { (31.5) } \\
\text { Cough: } 50 \text { (39.4) } \\
\text { Hemoptysis: } 34(26.8) \\
\text { Pneumonia: } 22 \text { (17.3) } \\
\text { Iterative pneumonia: } 9 \text { (7.1) } \\
\text { Endocrine syndrome: } 3(2.4) \\
\text { Carcinoid syndrome: } 1(0.8) \\
\text { Cushing syndrome: } 2(1.6) \\
\text { Acromegaly: } 1 \text { (0.8) }\end{array}$ \\
\hline Lung function & $\begin{array}{l}\text { FEV1: } 2259 \text { cc (mean) } \\
\% \text { FEV1: } 74.95 \% \text { (mean) } \\
\text { FVC: } 2859 \mathrm{cc} \text { (mean) } \\
\text { FVC: } 79.51 \% \text { (mean) } \\
\mathrm{PaO}^{2}: 77 \mathrm{~mm} \mathrm{Hg} \text { (mean) } \\
\text { PaCO }^{2}: 35 \mathrm{~mm} \mathrm{Hg} \text { (mean) }\end{array}$ \\
\hline
\end{tabular}

FEV1, forced expiratory volume in $1 \mathrm{~s}$; FVC, forced vital capacity.
Table 2 Pathological features

\begin{tabular}{ll}
\hline Patterns & Solid: $36(28.3 \%)$ \\
& Acinar: $18(14.2 \%)$ \\
& Fusocellular: $9(7.1 \%)$ \\
& Well differentiated: $21(16.5 \%)$ \\
& Moderately differentiated: $97(76.4 \%)$ \\
Tumour differentiation & Poorly differentiated: $9(7.1 \%)$ \\
& $4(3.1 \%)$ \\
Pleural invasion & $11(8.7 \%)$ \\
Angiolymphatic invasion & $1(0.8 \%)$ \\
Bone metaplasia & $1(0.8 \%)$ \\
Cellular pigmentation (melanin) & Synaptophysin: $33(26.0 \%)$ \\
Immunohistochemistry & Chromogranin A: $34(26.8 \%)$ \\
& Neuron-specific enolase: $20(15.7 \%)$ \\
&
\end{tabular}

biopsy was diagnostic in 41 cases (32.3\%). Nevertheless, surgery was necessary to obtain the definitive diagnosis of $\mathrm{AC}$ in 45 patients $(35.3 \%)$. Seventeen of these 45 cases were central tumours and another 28 cases were peripheral tumours.

In all, 77 lobectomies (60.65\%), 12 bi-lobectomies (9.4\%) and 22 pneumonectomies (17.3\%) were performed. Bronchoplastic procedures were associated in 6 cases (4.7\%): 4 sleeve lobectomies and 2 isolated bronchial resections. In 16 patients (12.6\%), SRs were carried out: 14 wedge resections and the 2 bronchial resections mentioned previously. There was no postoperative mortality in the series. Mean tumour size was $32.38 \mathrm{~mm}$ (SD: 16.170; range 9-99 mm). Pathological features are described in table 2 . Thirty-five cases $(27.6 \%)$ were pT1 tumours, $81(63.8 \%)$ pT2, $6(4.7 \%)$ pT3 and 5 were $(3.9 \%)$ pT4. Forty-three patients $(33.9 \%)$ presented some kind of nodal affection: $18 \mathrm{pN} 1$ (14.2\%), $24 \mathrm{pN} 2$ (18.9\%) and $1 \mathrm{pN} 3$ $(0.86 \%)$. From these $\mathrm{N}+$ patients, eight cases were classified as T3 or T4 tumours (table 3 ).

Multimodal therapy after surgery was indicated in an individualised manner. Eighteen patients underwent any kind of adjuvant treatment (11 ChT, 6 RT and 3 ChT-RT). Four patients of this group were N0 ( 3 ChT because of the size of the tumour (larger than $7 \mathrm{~cm}, \mathrm{cT} 3$ ) and $1 \mathrm{RT}$ because of sublobar resection). Fourteen of these patients were classified as $\mathrm{N}+$.

Thirty-two out of 127 patients (25.2\%) presented some kind of recurrence during the outcome: 5 corresponded to locoregional recurrences (3.9\%), 22 were distant metastasis $(17.3 \%)$ and 5 patients had both types $(3.9 \%)$. The most prevalent location for locoregional recurrence was mediastinal lymph nodes, while the liver was the most typical location for distant metastasis.

Twenty-three patients died during monitoring, 12 because of the tumour and 11 from other causes (not attributable to tumour progression). Median survival for death from any cause

Table 3 T-staging in $\mathrm{N}+$ cases

\begin{tabular}{lrrrr}
\hline & \multicolumn{1}{l}{$\mathbf{N}$} & & \\
\cline { 2 - 4 } Stage & $\mathbf{p N 1}$ & $\mathbf{p N 2}$ & $\mathbf{p N 3}$ & Total \\
\hline T & & & & \\
pT1 & 2 & 4 & 0 & 6 \\
pT2 & 12 & 16 & 1 & 29 \\
pT3 & 2 & 1 & 0 & 3 \\
pT4 & 2 & 3 & 0 & 5 \\
Total & 18 & 24 & 1 & 43 \\
\hline
\end{tabular}




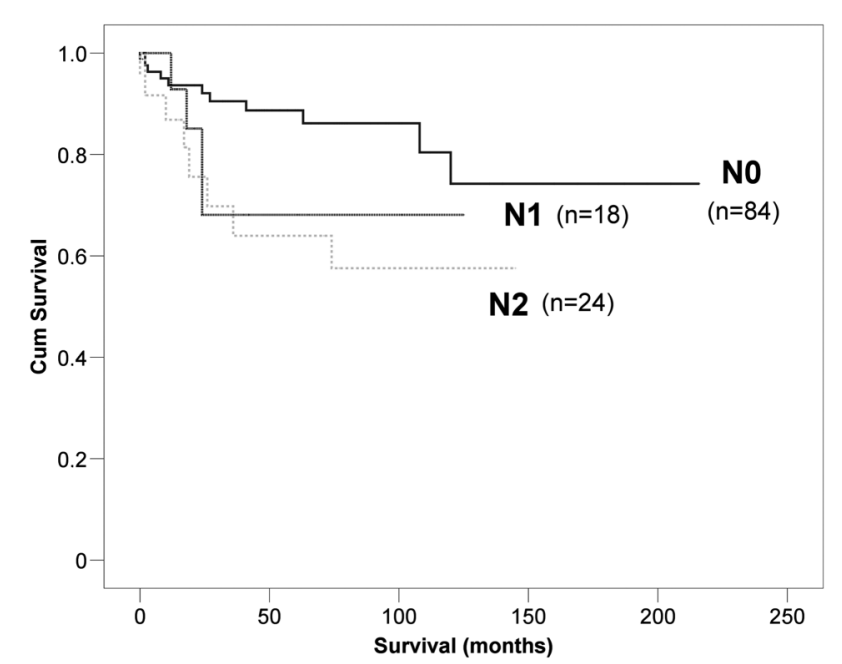

Figure 1 Prognostic influence of $\mathrm{N}$-status in atypical carcinoid. Univariable analysis (Kaplan-Meier) $(p=0.049)$.

in the AC follow-up was 47 months. Five-year overall survival rate in $\mathrm{AC}$ was $80 \%$. None of the pathological tumour characteristics (differentiation grade, tumour pattern, bone metaplasia and immunohistochemical markers) were found to be significant for survival influence. In a univariable analysis, T-status categories presented statistical signification related to survival of these patients $(p=0.005)$. As to the prognostic significance of nodal disease in survival of patients affected by AC, 5 -year survival for N0, N1 and N2 cases was 88\%, 68\% and $64 \%$, respectively. We discarded the only N3 case for prognostic analysis. When we compared N0 survival with $\mathrm{N}+$ survival in these patients, differences observed were statistically significant $(p=0.021)$ (figure 1$)$. In the $\mathrm{N}+$ patients, there were no statistical differences in survival or recurrence between patients receiving or not receiving adjuvant treatment. Six patients presented solitary M1 disease at the time of lung surgery (metastatic tumour was previously curatively treated). These M1 patients had a significantly worse survival prognosis than the M0 (estimated mean survival time 171.3 months in M0 group vs 73.7 months in M1 group; $p=0.040$ ) (table 4).

Recurrence also affected survival adversely. When we studied the prognostic behaviour of patients presenting locoregional recurrence, we found clinical differences. Estimated mean survival time for locoregional recurrence was 90.4 months $(95 \%$ CI 63.2 to 117.6 ), against 169.4 months for patients without locoregional recurrence (95\% CI 150.8 to 188.0). However, this difference was not statistically significant $(p=0.435)$. Patients who developed distant metastasis during follow-up presented significantly poorer survival than those who did not $(\mathrm{p}<0.001)$ (figure 2 ), presenting a 5 -year survival rate of $39 \%$. Median survival time for distant disease, locoregional disease and recurrence-free patients was 38, 114 and 180 months, respectively. In a multivariable analysis, the development of distant recurrence was demonstrated as the main independent risk factor for survival of these patients $(p<0.001$; $\mathrm{HR}=13.095$; 95\% CI for HR: 5.048 to 33.974 ).

Recurrence relationship between type of resection practiced and recurrence was assessed. We observed that patients who underwent SR developed locoregional recurrence more frequently (6 patients; $37.5 \%)$ than those who received LR (4 patients; 3.9\%) $(\mathrm{p}<0.001)$ (figure 3). Ninety-eight percent of patients who underwent LR were free of locoregional recurrence 2 years after surgery ( $71 \%$ for the SR group).

When analysing distant recurrence, tumour size according to TNM system cut-off presented clinical differences in this aspect, but without statistical significance $(p=0.550)$, possibly due to sample size. With respect to distant recurrence, T-status did present statistical differences related to the time to metastasis in the univariable recurrence analysis $(\mathrm{p}<0.001)$ (figure 4).

Another important topic is the relationship between nodal invasion and recurrence. We observed that the higher the $\mathrm{N}$-status of the patient, the higher the frequency of distant metastasis $(16.7 \%, 27.8 \%$ and $33.4 \%$ for $\mathrm{N} 0, \mathrm{~N} 1$ and N2, respectively). For locoregional recurrence, differences were not so important, perhaps because of the few cases collected for this group $(7.1 \%, 5.5 \%$ and $8.3 \%$ for each step of $\mathrm{N}$-status). Although we could not demonstrate statistical signification for these clinical differences $(p=0.961$ for locoregional recurrence and $\mathrm{p}=0.154$ for distant metastasis), we found significant differences between $\mathrm{N} 0$ and $\mathrm{N}+$ patients when considering any kind of recurrence (locoregional and/or distant) $(p=0.019)$ (figure 5). In fact, when we analysed the frequency of locoregional recurrence between the LR group and the SR, stratifying data by $\mathrm{N}$-status, we could confirm statistical differences $(\mathrm{p}<0.001)$. The estimated mean for time to locoregional recurrence in $\mathrm{N} 0$ patients was 204.33 months (95\% CI 187.92 to 220.74 ) for the

Table 4 Kaplan-Meier univariable survival analysis

\begin{tabular}{|c|c|c|c|c|c|}
\hline Variable & Categories & n (events) & 2 years survival $(95 \% \mathrm{CI})$ & 5 years survival $(95 \% \mathrm{CI})$ & p Value \\
\hline $\mathrm{T}$ & $\begin{array}{l}\mathrm{T} 1 \\
\mathrm{~T} 2 \\
\mathrm{~T} 3 \\
\mathrm{~T} 4\end{array}$ & $\begin{array}{c}35(2) \\
81(18) \\
6(1) \\
5(2)\end{array}$ & $\begin{array}{l}0.935(0.847 \text { to } 1.023) \\
0.843(0.757 \text { to } 0.929) \\
1 \\
0.8(0.449 \text { to } 1.151)\end{array}$ & $\begin{array}{l}0.935(0.847 \text { to } 1.023) \\
0.793(0.695 \text { to } 0.891) \\
0.667(0.134 \text { to } 1.200) \\
0.400(-0.182 \text { to } 0.982)\end{array}$ & 0.005 \\
\hline $\mathrm{N}$ & $\begin{array}{l}\text { N0 } \\
\text { N1 } \\
\text { N2 }\end{array}$ & $\begin{array}{l}84(11) \\
18(4) \\
24(8)\end{array}$ & $\begin{array}{l}0.921(0.859 \text { to } 0.983) \\
0.681(0.420 \text { to } 0.942) \\
0.756(0.566 \text { to } 0.946)\end{array}$ & $\begin{array}{l}0.887(0.813 \text { to } 0.961) \\
0.681(0.420 \text { to } 0.942) \\
0.640(0.422 \text { to } 0.858)\end{array}$ & 0.049 \\
\hline M (preoperative) & $\begin{array}{l}\text { M0 } \\
\text { M1 }\end{array}$ & $\begin{aligned} 121 & (20) \\
6 & (3)\end{aligned}$ & $\begin{array}{l}0.872(0.939 \text { to } 0.805) \\
0.667(0.291 \text { to } 1.043)\end{array}$ & $\begin{array}{l}0.823(0.901 \text { to } 0.745) \\
0.667(0.291 \text { to } 1.043)\end{array}$ & 0.040 \\
\hline Distant recurrence & $\begin{array}{l}\text { No } \\
\text { Yes }\end{array}$ & $\begin{aligned} 100(7) \\
27(16)\end{aligned}$ & $\begin{array}{l}0.952(0.905 \text { to } 0.999) \\
0.563(0.367 \text { to } 0.759)\end{array}$ & $\begin{array}{l}0.923(0.864 \text { to } 0.982) \\
0.465(0.669 \text { to } 0.261)\end{array}$ & 0.000 \\
\hline Pneumonectomy & $\begin{array}{l}\text { No } \\
\text { Yes }\end{array}$ & $\begin{array}{c}105(17) \\
22(6)\end{array}$ & $\begin{array}{l}0.736(0.534 \text { to } 0.938) \\
0.889(0.824 \text { to } 0.954)\end{array}$ & $\begin{array}{l}0.669(0.448 \text { to } 0.890) \\
0.848(0.772 \text { to } 0.924)\end{array}$ & 0.157 \\
\hline Chemotherapy & $\begin{array}{l}\text { No } \\
\text { Yes }\end{array}$ & $\begin{array}{c}114(18) \\
13(5)\end{array}$ & $\begin{array}{l}0.869(0.802 \text { to } 0.936) \\
0.788(0.525 \text { to } 1.051)\end{array}$ & $\begin{array}{l}0.844(0.771 \text { to } 0.917) \\
0.563(0.240 \text { to } 0.886)\end{array}$ & 0.327 \\
\hline
\end{tabular}




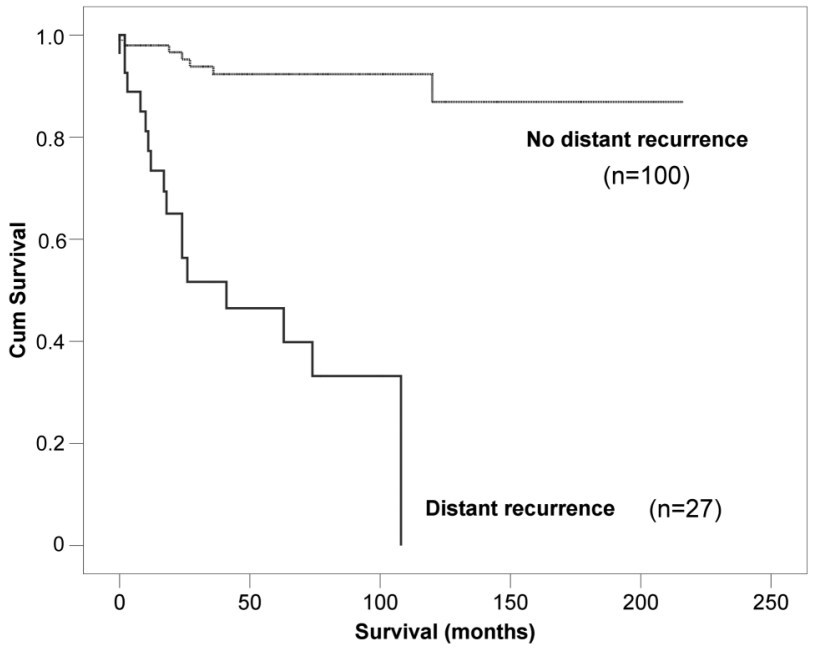

Figure 2 Prognostic influence of distant metastasis during the outcomes. Univariable analysis (Kaplan-Meier) $(p<0.001)$.

LR and 83.82 months (95\% CI 59.99 to 107.65 ) for the SR group; in $\mathrm{N}+$ patients, it was 131.98 months $(95 \% \mathrm{CI} 115.14$ to 148.82) for the LR group, and 57.14 months (95\% CI 30.37 to 83.92) for the SR group. We did not find any differences for the case of distant recurrence in this aspect. Finally, patients classified as M1 (preoperatively treated tumours) at the time of lung surgery, presented shorter locoregional $(p=0.004)$ and distant $(\mathrm{p}<0.001)$ recurrence-free intervals than M0 cases (estimated mean for time to locoregional recurrence of 195 months in M0 patients vs 44.8 months in M1 patients; 168 months vs 14.5 months, respectively, for the time to distant recurrence).

In a multivariable analysis, SR was considered as an independent prognostic factor to predict locoregional recurrence in these patients $(\mathrm{p}=0.002 ; \mathrm{HR}=18.111 ; 95 \%$ CI for HR: 2.893 to 113.362).

Finally, the prognostic effect of adjuvant ChT was analysed. Patients who underwent adjuvant ChT did not present any statistical differences regarding survival and recurrence $(p=0.327$ and $p=0.294$, respectively) (table 4 ). At any rate, adjuvant treatment was infrequent and varied considerably, so it is difficult to arrive at any further conclusions.

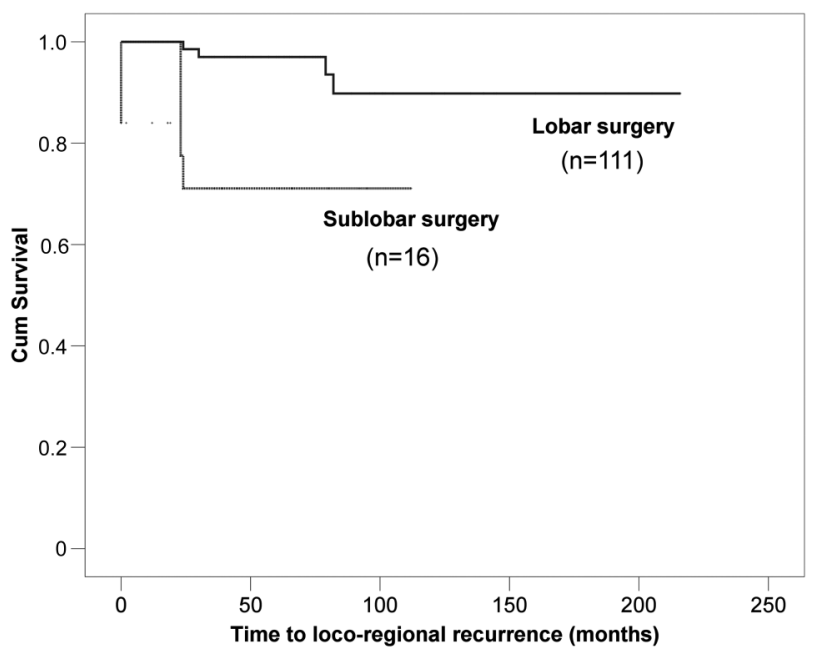

Figure 3 Influence of the extent of resection in locoregional recurrence. Univariable analysis (Kaplan-Meier) $(p<0.001)$.

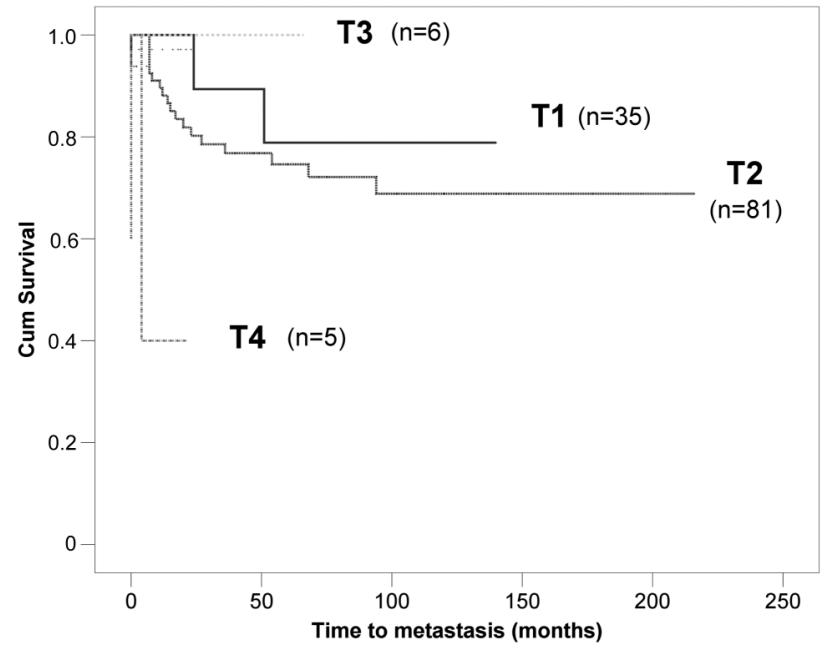

Figure 4 Influence of T-status in distant recurrence. Univariable analysis (Kaplan-Meier) $(\mathrm{p}<0.001)$.

\section{COMMENT}

Atypical carcinoid represents an infrequent lung neoplasm, included in the neuroendocrine spectrum and defined by Travis ${ }^{3}$ modified histological criteria. The criteria for diagnosis of AC includes the existence of 2-10 mitoses per $2 \mathrm{~mm}^{2}$ area, or the presence of small punctuate foci of necrosis. Additionally, nucleoli can be seen in AC. ${ }^{9}$ Recently, the seventh edition of the Union for International Cancer Control/American Joint Committee on Cancer TNM system has been recommended for the classification of pulmonary carcinoid tumours. ${ }^{8}$ Frequency ranges for $\mathrm{AC}$ reported in the literature vary from $14 \%$ to $33 \%$ of carcinoid tumours, ${ }^{10-13}$ which is consistent with our data. Almost one-third of patients remain asymptomatic at the moment of the diagnosis, ${ }^{14}$ which agrees with our observations. Accepting these facts, although many AC characteristics are known, the role of prognostic factors is not completely defined.

Intermediate prognosis in $\mathrm{AC}$ has been described for many years. Garcia-Yuste and colleagues, ${ }^{10}$ Cardillo and colleagues ${ }^{15}$ and Filosso and associates ${ }^{16}$ reported an improved prognosis of $\mathrm{N} 0$ patients compared to $\mathrm{N}+$ cases. Stamatis and colleagues ${ }^{17}$

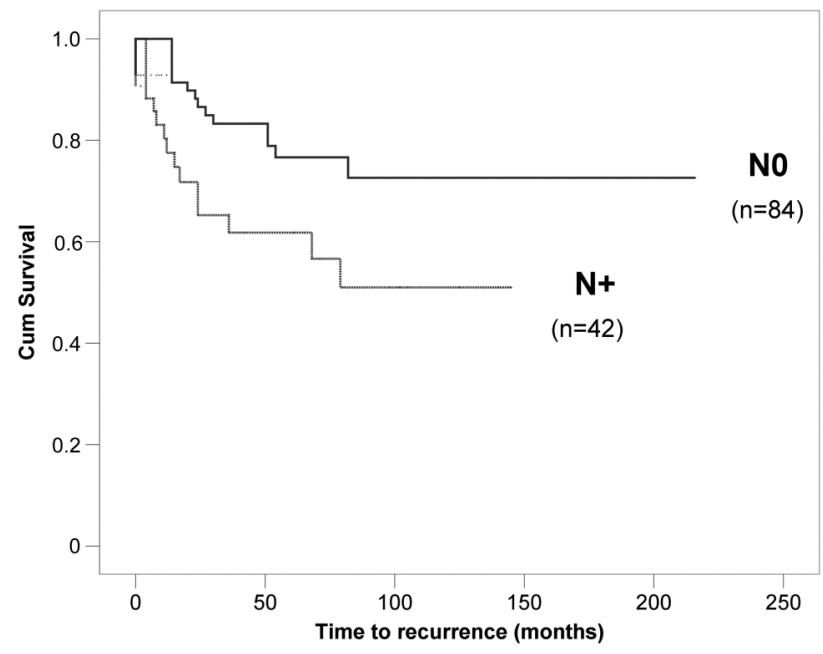

Figure 5 Influence of nodal affection in global recurrence (locoregional and/or distant). Univariable analysis (Kaplan-Meier) $(p=0.019)$. 
reported a high frequency of nodal hilar and mediastinal metastases in AC, but they did not indicate any prognostic factors for this kind of neuroendocrine neoplasms. Thomas and associates ${ }^{12}$ found $\mathrm{AC}$ histology to be an important prognostic factor related to survival of patients with carcinoid tumours. Many other authors agree with this observation. ${ }^{18}{ }^{19}$ However, the authors did not describe specific prognostic factors for AC. Although tumour size and recurrences are related to life expectancy, in our experience, nodal disease remains an important prognostic factor to predict survival and recurrence.

Nodal disease is a frequent feature in AC. In fact, its relationship with prognosis has been reported in these patients. ${ }^{20}$ The investigation for lymph node metastases seems to be an unavoidable requisite to establish prognosis and to evaluate therapeutic strategies. ${ }^{11}$ Invasive mediastinal staging with mediastinoscopy inspection has been recommended for $\mathrm{cN} 1$ and $\mathrm{cN} 2$ tumours. ${ }^{14}$ Our data support this statement, because of the poorer prognosis of patients with nodal involvement as well as the higher frequencies of recurrences in this group. This supports the requirement of an appropriate and reliable mediastinal staging (endobronchial or transesophageal endoscopic ultrasoundguided needle aspiration biopsy, mediastinoscopy or thoracoscopy) before surgical treatment.

In the same line as our work, nodal involvement and complete resection were recognised as prognostic predictors in $\mathrm{AC}$ during the 2007 International Workshop on Advances in Pulmonary Neuroendocrine Tumours. ${ }^{21}$ Intermediate survival for patients with AC was reported, with distal site recurrence being more common than local recurrence. In our experience, nodal affection and recurrence are closely related. Davini and colleagues $^{13}$ stated that ACs are more likely to recur regardless of stage, but their data did not support this affirmation. By contrast, Rea and colleagues ${ }^{11}$ observed that $50 \%$ of recurrences observed in $\mathrm{AC}$ were $\mathrm{N}+$. Other authors have noted the relevance of lymph node micrometastasis detected by immunohistochemical techniques, ${ }^{22}$ worsening the prognosis of these patients for survival and recurrence. This would support radical lymphadenectomy in these cases. The analysis of our data allows us to demonstrate that a higher $\mathrm{N}$-status influences the probability of tumour recurrence, confirming the need to determine lymph node involvement systematically in these patients.

Surgery represents the cornerstone of treatment of AC tumours. Complete standard surgical resection and mediastinal lymph node dissection is the treatment of choice. Atypical resections have been related to an increased number of recurrences in $\mathrm{AC}^{23}$ In our series, $24 \%$ of patients who underwent SR presented locoregional recurrence at some time during follow-up. Furthermore, patients who underwent these SRs presented a higher incidence of locoregional recurrence when compared with LR, independently of $\mathrm{N}$-status. This observation could suggest that the magnitude of resection is a predictive variable for locoregional recurrence, not only lymph node invasion. Emphasising this issue, Yendamuri and colleagues ${ }^{24}$ have attempted to ascertain whether SRs are sufficient for carcinoid tumours. They have recommended avoiding lobectomies in typical carcinoid tumours, although they find the atypical histology to be an adverse prognostic factor. Nevertheless, they make no indication about AC. In the same direction, Fox and colleagues $^{25}$ have recently published the experience of the Surveillance Epidemiology and End Results (SEER) database about this aspect. Even when they do not find any diseasespecific mortality in patients undergoing SR because of AC, the authors make no recommendation regarding these tumours.
Moreover, they could not perform any recurrence analysis because of the lack of information in coding the data from SEER database. Our series, one of the largest published to date, specifically focused on AC, shows that SR should be reserved for patients at high cardiopulmonary risk, based on locoregional recurrence rates. As to surgical indication in cases of M1 preoperatively treated patients, we did not find any recommendations in the literature. In our experience, these patients present lower life expectancy and a higher recurrence rate than those staged as M0.

Focusing on adjuvant treatment of these tumours, there is no consensus about which patients could benefit from multimodal therapy. Some authors have tried to identify potential candidates for adjuvant ChT. Survival of $\mathrm{N}+\mathrm{AC}$ patients is poorer than survival in $\mathrm{N} 0$ patients. That is the reason why these patients could be candidates for adjuvant therapy. However, there is insufficient evidence to assess the efficacy of this treatment and the agent of choice. ${ }^{21}$ Data about this are scarce and inconsistent in our series, so we cannot draw a conclusion on the results obtained in this aspect.

In conclusion, nodal status, extent of resection and recurrence will affect prognostic evolution of these patients. Bearing in mind these data, standard surgical resection with radical lymphadenectomy is essential. In our experience, limited resections should be avoided except for special patient conditions, because of higher recurrence. Further studies with larger sample sizes and new prognostic marker analyses are recommended.

\section{Author affiliations}

${ }^{1}$ Department of Thoracic Surgery, University Hospital, Vigo, Spain

${ }^{2}$ Department of Thoracic Surgery, University Hospital, Valladolid, Spain

${ }^{3}$ Department of Thoracic Surgery, Virgen de las Nieves University Hospital, Granada, Spain

${ }^{4}$ Department of Thoracic Surgery, Reina Sofia University Hospital, Cordoba, Spain

${ }^{5}$ Department of Thoracic Surgery, Ramon y Cajal University Hospital, Madrid, Spain

${ }^{6}$ Department of Thoracic Surgery, Virgen del Rocio University Hospital, Seville, Spain

${ }^{7}$ Department of Thoracic Surgery, La Princesa Hospital, Madrid, Spain

${ }^{8}$ Department of Thoracic Surgery, General University Hospital, Valencia, Spain

${ }^{9}$ Department of Thoracic Surgery, Carlos Haya University Hospital, Malaga, Spain

${ }^{10}$ Spanish Multicenter Study of Neuroendocrine Tumours of the Lung (EMETNE-

SEPAR), Valladolid, Spain

Collaborators Addendum: Emetne members: Mariano García-Yuste, MD PhD, Jose-Maria Matilla, MD PhD, Felix Heras, MD PhD, and Henar Borrego, MD (University Hospital, Valladolid); Ignacio Escobar, MD and Joan Moya, MD, PhD (Bellvitge Hospital, Barcelona); Juan Lago, MD, David Saldaña, MD PhD and Pilar Garrido, MD (Ramon-y-Cajal Hospital, Madrid); Francisco Cerezo, MD and Javier Algar, MD (Reina-Sofia Hospital, Cordoba); Federico Gonzalez-Aragoneses, MD, Carlos Simon, MD, Emilio Alvarez, MD and Maria Cebollero, MD (Gregorio-Marañon Hospital, Madrid); Jose-Manuel Rodriguez-Paniagua, MD (University Hospital, Alicante); Ricardo Guijarro, MD, PhD and Antonio Arnau, MD, PhD (General-University Hospital, Valencia); Luis Lopez-Rivero, MD, PhD, Santiago Quevedo, MD and Maria-Carmen Camacho, MD (Insular Hospital, Las-Palmas); Julio Astudillo, MD and Javier Perez, MD (Germans-Trias-Pujol Hospital, Badalona); Laureano Molins, MD (Clinic Hospital, Barcelona); Jose-Manuel Mier (Sagrado-Corazón Hospital, Barcelona); Antonio Cueto, MD, Abel Sanchez-Palencia, MD and Angel Concha, MD (Virgen-de-las-Nieves Hospital, Granada); Jorge Freixinet, MD, PhD, Pedro Rodriguez, MD and Teresa Romero, MD (Dr-Negrin Hospital, Las Palmas); Juan Torres, MD, PhD and Juan Bermejo, MD (Virgen-Arrixaca Hospital, Murcia); Nicolas Moreno, MD, PhD and Ana Blanco, MD (Virgen-Rocio Hospital, Sevilla); Jose-Maria Borro, MD and Mercedes de-la-Torre, MD and Ana Capdevilla, MD (University Hospital, Coruña); Ramon Moreno, MD (La-Princesa Hospital, Madrid); Mireia Serra and Ramon Rami-Porta, MD (Mutua-Terrassa Hospital, Terrassa); Ricardo Arrabal, MD, and Antonio Benitez, MD (Carlos-Haya Hospital, Malaga); Andres Varela, MD and Mar Cordoba, MD

(Puerta-Hierro-Majadahonda Hospital, Madrid); Miguel-Angel Cañizares MD, PhD, Eva Garcia-Fontan, MD, Montserrat Blanco-Ramos, MD, PhD and Ana Gonzalez-Piñeiro, MD (University Hospital, Vigo); Ignacio Muguruza, MD, PhD and José Zapatero, MD, PhD, (Fundación-Jiménez-Díaz Hospital, Madrid); Juan-Jose Rivas and MD, Patricia Menal, MD (Miguel-Servet Hospital, Zaragoza); Genaro Galan, MD, PhD (Clinic Hospital, Valencia); and Emilio Ansotegui, MD (La-Fe Hospital, Valencia). 
Contributors MAC was the main writer of the text. JMM, MG-Y and EG-F worked as internal revisers. MAC and AC coworked in the initial design of the project. AG-P assessed about pathological aspects of the paper. JA, NM-M, IM studied the state of art in published data about atypical carcinoid, introducing discussion topics. RG, RA and RA verified reliability of data. MAC and JMM performed statistical analysis, with the support of Statistics Department of Valladolid University. All of them participated in obtaining data for the database and all of them revised the final manuscript. EMETNE-SEPAR is the acronym of the Spanish Multicenter Study of Neuroendocrine Tumours of the Lung. All the authors take responsibility for the content of this work.

\section{Competing interests None.}

Ethics approval Ethics Committee from every participant hospital.

Provenance and peer review Not commissioned; externally peer reviewed.

\section{REFERENCES}

1 Bertino EM, Confer PD, Colonna JE, et al. Pulmonary neuroendocrine/Carcinoid tumors. Cancer 2009;1:4434-41.

2 Arrigoni MG, Woolner LB, Bernatz PE. Atypical carcinoid tumors of the lung J Thorac Cardiovasc Surg 1972:64:413-21.

3 Travis W, Rush W, Flieder DB, et al. Survival analysis of 200 pulmonary neuroendocrine tumors with clarification criteria of atypical carcinoid and its separation from typical carcinoid. Am J Surg Pathol 1998;22:934-44.

4 Rekhtman N. Neuroendocrine tumors of the lung. An update. Arch Pathol Lab Med 2010;134:1628-38

5 Modlin IM, Sandor A. An analysis of 8305 cases of carcinoid tumors. Cancer 1997:79:813-29.

6 Fink $G$, Krelbaum T, Yellin A, et al. Pulmonary carcinoid: presentation, diagnosis and outcome in 142 cases in Israel and review of 640 cases from the literature. Chest 2001;119:1647-51.

7 Skuladottir $\mathrm{H}$, Hirsh FR, Hansen $\mathrm{HH}$, et al. Pulmonary neuroendocrine tumors: incidence and prognosis of histological subtypes. A population-based study in Denmark. Lung Cancer 2002;37:127-35.

8 Travis WD, Giroux DJ, Chansky K, et al. The IASLC Lung Cancer Staging Project: proposals for the inclusion of bronchopulmonary carcinoid tumors in the forthcoming (seventh) edition of the TNM Classification for Lung Cancer. J Thorac Oncol 2008;3:1213-23.

9 Travis WD. Advances in neuroendocrine lung tumors. Ann Oncol 2010;21(Suppl 7): vii65-71.
10 García-Yuste M, Matilla JM, Cueto A, et al. Typical and atypical carcinoid tumours: analysis of the experience of the Spanish Multicentric Study of Neuroendocrine Tumours of the lung. Eur J Cardiothorac Surg 2007:31:192-7.

11 Rea F, Rizzardi G, Zuin A, et al. Outcome and surgical strategy in bronchial carcinoid tumors: single institution experience with 252 patients. Eur J Cardiothorac Surg 2007;31:186-91

12 Thomas CF, Tazelaar HD, Jett JR. Typical and atypical pulmonary carcinoids: Outcome in patients presenting with regional lymph node involvement. Chest 2001;119:1143-50.

13 Davini F, Gonfiotti A, Comin C, et al. Typical and atypical carcinoid tumors: 20-year experience with 89 patients. J Cardiovasc Surg 2009;50:807-11.

14 Detterbeck FC. Management of carcinoid tumors. Ann Thorac Surg 2010;89:998-1005.

15 Cardillo G, Sera F, Di Martino M, et al. Bronchial carcinoid tumors: nodal status and long-term survival after resection. Ann Thorac Surg 2004;77:1781-5.

16 Filosso PL, Rena O, Donati G, et al. Bronchial carcinoid tumors: surgical management and long-term outcome. J Thorac Cardiovasc Surg 2002;123:303-9.

17 Stamatis G, Freitag L, Greschuchna D. Limited and radical resection for tracheal and bronchopulmonary carcinoid tumour. Report on 227 cases. Eur J Cardiothorac Surg 1990;4:527-32.

18 Aydin E, Yazici U, Gulgosteren M, et al. Long-term outcomes and prognostic factors of patients with surgically treated pulmonary carcinoid: our institutional experience with 104 patients. Eur J Cardiothorac Surg 2011;39:549-54.

19 Cao C, Yan TD, Kennedy C, et al. Bronchopulmonary carcinoid tumors: long-term outcomes after resection. Ann Thorac Surg 2011;91:339-43.

20 García Yuste M, Matilla JM, González Aragoneses F. Neuroendocrine tumors of the lung. Curr Opin Oncol 2008:20:148-54.

21 Lim E, Goldstraw P, Nicholson AG, et al. Proceedings of the IASLC International Workshop on Advances in Pulmonary Neuroendocrine Tumors 2007. J Thorac Oncol 2008:3:1194-201.

22 Mineo TC, Guggino G, Mineo D, et al. Relevante of lymph node micrometastases in radically resected endobronchial carcinoid tumors. Ann Thorac Surg 2005;80:428-32.

23 Mezzetti M, Raveglia F, Panigalli T, et al. Assessment of outcomes in typical and atypical carcinoids according to latest WHO classification. Ann Thorac Surg 2003:76:1838-42

24 Yendamuri S, Gold D, Jayaprakash V, et al. Is sublobar resection sufficient for carcinoid tumors? Ann Thorac Surg 2011;92:1774-8.

25 Fox M, Van Berkel V, Bousamra M II, et al. Surgical management of pulmonary carcinoid tumors: sublobar resection versus lobectomy. Am J Surg 2013;205:200-8 